\title{
Abnormal uterine bleeding: a critical analysis of two diagnostic methods
}

\author{
Manisha Jain ${ }^{1 *}$, Anjali Kanhere ${ }^{1}$, Ajay Kumar Jain ${ }^{2}$ \\ ${ }^{1}$ Department of Obstetrics \& Gynaecology, ${ }^{2}$ Department of Surgery, Peoples' College of Medical Sciences \& Research \\ Centre, Bhopal- 462037, Madhya Pradesh, India
}

Received: 10 November 2013

Accepted: 5 December 2013

\author{
*Correspondence: \\ Dr. Manisha Jain, \\ E-mail: mnishu2002@yahoo.com
}

(C) 2014 Jain M et al. This is an open-access article distributed under the terms of the Creative Commons Attribution Non-Commercial License, which permits unrestricted non-commercial use, distribution, and reproduction in any medium, provided the original work is properly cited.

\begin{abstract}
Background: Abnormal Uterine Bleeding (AUB) is one of the most common reasons for women to seek gynaecology consultation. The underlying causes in AUB are many and identifying the exact cause can be a real challenge to the treating gynaecologists. Objectives of current study are to study the common etiology of AUB and to study and correlate the diagnoses of Trans Vaginal Sonography (TVS) and Diagnostic Hysteroscopy (DH) with histopathology diagnosis.

Methods: One hundred and thirteen women with AUB were enrolled and evaluated by conventional TVS and DH. The findings were correlated with histopathology diagnosis. The sensitivity, specificity and positive and negative predictive value of TVS and DH were calculated after comparison with final histopathology diagnosis.

Results: Fibroids and polyps were the two commonest structural lesions in AUB. For submucosal fibroids, the sensitivity and specificity of DH was found to be $92 \%$ and $99 \%$ respectively while that of TVS was found to be $85 \%$ and $100 \%$ respectively. For polyps, the sensitivity and specificity of DH was found to be $91 \%$ and $98 \%$ respectively and that of TVS was 68\% and $93 \%$ respectively. The coefficient of correlation for DH was better than that of TVS.

Conclusions: Fibroids and polyps are the two commonest structural lesions causing AUB in the women of reproductive age group. TVS has a role as primary screening method for the initial work-up AUB before resorting to invasive procedure such as hysteroscopy.
\end{abstract}

Keywords: Abnormal uterine bleeding, Diagnostic hysteroscopy, Transvaginal sonography

\section{INTRODUCTION}

Abnormal uterine bleeding is a cause of major health care burden for the woman and the society as a whole. Besides significant physical discomfort it is also responsible for much financial and psychological impact on the woman. About $30 \%$ of women seek medical assistance for AUB during their reproductive age group and about one third of hysterectomies are carried out for AUB alone. AUB ranks next only to the abnormal vaginal discharge among the total gynaecology OPD attendance.
The list of underlying pathologies in AUB is vast and requires meticulous evaluation not only to pin-point the cause but also to exclude malignancy in women of advanced age. Also from the patients, perspective determining the exact cause has important implications on therapeutic decisions. Though, clinical evaluation provides the foundation, contemporary work up also relies on the diagnostic procedures. Recently, with availability of newer and advanced diagnostic tools more and more of structural intrauterine abnormalities are being detected in cases of abnormal uterine bleeding. Office hysteroscopy with directed biopsy although, being promoted as potential minimally invasive tool in primary 
evaluation of AUB, is often not available in every unit. Frequently performed as an inpatient procedure, diagnostic hysteroscopy thus adds the risk of anaesthesia and surgical cost of the procedure. TVS being simple, rapid, painless, non- invasive and cost - effective brings about indirect assessment of structural intrauterine pathologies. Also the anatomy of adnexae and surrounding tissues is better delineated on sonography. Present study was undertaken to evaluate and compare the findings of the two commonly employed diagnostic tools in the work up of AUB.

\section{METHODS}

A prospective diagnostic study was conducted in the Department of Obstetrics and Gynecology at People's College of Medical Sciences and Research Centre and People's Hospital, Bhanpur, Bhopal from Dec 2006 to Dec 2012. The study protocol received approval by Institutional research advisory committee and ethics committee. All women with abnormal uterine bleeding attending outpatient department (OPD) of Obstetrics and Gynecology, People's Hospital, Bhanpur, Bhopal, were offered voluntary participation in the study after written informed consent. Every participant was free to withdraw from the study at any time of study duration for any reason.

One hundred and thirteen patients with AUB were recruited and subjected to detailed questionnaire about patterns of abnormal bleeding, significant medical and surgical history in past and intake of any drugs or hormonal preparation including details of prior treatment if administered. They were then subjected to serial trans-vaginal scan, diagnostic hysteroscopy and dilatation and curettage (D\&C) after thorough clinical examination and work- up. All women with profuse uterine bleeding, haemodynamically unstable subjects, pregnant or postpartum cases and women with severe PID or overt genital malignancy were excluded from the study. In our study we did not include girls below eighteen years of age. Three women in whom hysteroscope could not be negotiated were also excluded out of the study.

\section{Transvaginal sonography}

TVS was performed by two separate researchers from the department of radiodiagnosis using GE logic - 5 machine with $8 \mathrm{MHz}$ transvaginal probe, independent of phase of cycle. The uterine size was measured in both the sagittal and coronal planes and double layer endometrial stripe thickness was estimated as the thickest part in the sagittal plane with the entire endocervical and endometrial stripe visible. The examination was completed with a note on adnexal pathology, if present.

Diagnostic hysteroscopy: After informed consent and pre-operative work - up, DH was carried out in the operation theatre under intravenous sedation and paracervical block (lignocaine 1\%). Using rigid $8 \mathrm{~mm}$ hysteroscope with double flow sheath and $30 *$ fore oblique view (Pro - MIS CE 0123) the procedure was carried out preferably in proliferative phase of menstrual cycle. Double flow sheath was preferred unless the cervix could not be dilated adequately in which case a single flow $4 \mathrm{~mm}$ sheath was used. Double flow sheath by continually washing out blood and debris gave better vision. Hysteroscopy was carried out using standard approach under all aseptic precautions. Normal saline (1 liter) infused by pneumatic cuff under manometric pressure control between $100-120 \mathrm{~mm}$ of $\mathrm{Hg}$ was used to distend the uterine cavity. A cold light source of high intensity and fibre optic cable was used for illumination and systematic inspection of the endocervical canal, internal os and entire uterine cavity was carried out. The procedure was monitored using endoscopic single chip video camera and images projected onto the monitor visible to us. Hysteroscopic findings were recorded as normal, atrophic, submucosal myoma, polyp, endometrial hyperplasia and endometritis as per the view.

\section{Dilatation and curettage}

All patients underwent thorough endometrial curettage from all the walls of the uterine cavity using a sharp curettage. Specimen thus obtained was sent in $10 \%$ formalin for histopathological examination by the pathologist who was blinded to the findings of TVS and DH. In patients with appropriate indications hysterectomy was done and histopathology report thus obtained was used for correlation.

The sensitivity, specificity and positive and negative predictive value of TVS and DH were calculated after comparison with final diagnosis. The agreement of TVS and $\mathrm{DH}$ with final diagnosis was calculated using coefficient of correlation.

\section{RESULTS}

\section{Characteristics of patients}

One hundred and ten women of abnormal uterine bleeding were included and evaluated in this study with the mean age 41.9 years (range: 20 to 65 years). Maximum (75\%) women were in the age group of $31-$ 45 years with thirteen $(11.8 \%)$ cases presenting in postmenopausal age group as post-menopausal bleed. Menorrhagia (34.5\%) was the most common presentation followed by metrorrhagia $(21.8 \%)$. Seven $(6.3 \%)$ women presented as postcoital bleed and thirteen (11.8\%) had postmenopausal bleed.

Intrauterine pathology was confirmed in sixty- two (56 $\%$ ) cases after histological correlation. Fibroids were the most common etiology behind the abnormal bleeding, seen in $28(25 \%)$ cases while polyps were the next common etiology noted in $22(20 \%)$ cases. Among twenty eight cases of fibroid, submucosal fibroids were 
present in $24(22 \%)$ cases and four women had intramural fibroids. Four women with submucosal fibroid also had co-existent intramural fibroids. Eleven (10\%) subjects had simple endometrial hyperplasia without atypia either as isolated pathology or coexistent with other pathology. Seven $(6.3 \%)$ cases of postmenopausal bleed had atrophic endometrium while adenomyosis was diagnosed in fifteen $(13.6 \%)$ cases. None of the patient in our series was detected to have atypical hyperplasia or malignancy. Endometrial hyperplasia and atrophy were noted in older age groups while benign pathologies (fibroid and polyp) were seen predominantly in younger women (Table 1).

\section{Transvaginal sonography findings}

Distribution of endometrial stripe thickness measurement for different etiology is given in Table 2.

The mean endometrial thickness for all was $9.56 \mathrm{~mm}$ (SD 4.27). The measurements were affected by the base of the polyp, phase of the menstrual cycle and whether the woman was in bleeding phase at the time of sonographic examination. TVS was good in defining the myometrial echotexture and anatomy of surrounding structures especially the adnexa. Six cases were diagnosed to have coexistent simple ovarian cysts. Ten out of fifteen cases of adenomyosis were picked up on sonography. Besides a vague pelvic discomfort during the procedure there was no other significant complaint from the patients. The diagnostic performance of TVS in terms of the sensitivity, specificity, positive predictive value and negative predictive value for different pathology is shown in table 3 .

Table 1: Showing the distribution of different etiology in relation to respective mean age $(n=110)$.

\begin{tabular}{|llll|}
\hline Final diagnosis & $\begin{array}{l}\text { Mean Age } \\
\text { (years) }\end{array}$ & $\begin{array}{l}\text { Total no. of } \\
\text { cases }\end{array}$ & $\%$ \\
\hline Proliferative & 39.29 & 34 & $30.9 \%$ \\
\hline Secretory & 31.33 & 06 & $5.4 \%$ \\
\hline Atrophic & 55.86 & 7 & $6.3 \%$ \\
\hline Fibroid $^{\#}$ & 43.04 & $28^{\#}$ & $25.4 \%$ \\
\hline Polyp $^{\wedge}$ & 42.17 & $22^{\wedge}$ & $20 \%$ \\
\hline Adenomyosis & 44.2 & 15 & $13.6 \%$ \\
\hline $\begin{array}{l}\text { Endometrial } \\
\text { hyperplasia }\end{array}$ & 48.0 & 11 & $10 \%$ \\
\hline $\begin{array}{l}\text { Endometritis, } \\
\text { CuT }\end{array}$ & 42 & 01 & \\
\hline Total & 41.91 & $124^{*}$ & \\
\hline
\end{tabular}

$* \mathrm{n} \neq 110$ as 5 patients had polyp and endometrial hyperplasia ; and 9 patients had fibroid with adenomyosis;

${ }^{\#}$ Fibroid $\quad-24$ patients had submucous fibroid

- 04 patients had intramural fibroid

- 04 patients had submucous and intramural fibroid
Table 2: Showing distribution of endometrial thickness ( $\mathrm{mm}$ ) for different etiology as measured on transvaginal sonography.

\begin{tabular}{|c|c|c|c|c|c|}
\hline $\begin{array}{l}\text { Endometrial } \\
\text { thickness }\end{array}$ & \multirow{2}{*}{$\begin{array}{l}\text { Total } \\
\text { Cases }\end{array}$} & \multirow{2}{*}{$\begin{array}{l}<5 \\
\mathbf{m m}\end{array}$} & \multirow{2}{*}{$\begin{array}{l}5-15 \\
\mathrm{~mm}\end{array}$} & \multirow{2}{*}{$\begin{array}{l}\geq 15 \\
\mathrm{~mm}\end{array}$} & \multirow{2}{*}{$\begin{array}{l}\text { Mean } \\
\text { ET } \\
(\mathrm{mm})\end{array}$} \\
\hline Etiology & & & & & \\
\hline Proliferative & 34 & - & 34 & - & 7.88 \\
\hline Secretory & 06 & - & 06 & - & 9.43 \\
\hline Atrophic & 07 & 05 & 02 & - & 4.29 \\
\hline Fibroid & 28 & 02 & 24 & 02 & 9.50 \\
\hline Polyp & 22 & - & 13 & 09 & 15.1 \\
\hline Adenomyosis & 15 & 01 & 14 & - & 9.2 \\
\hline $\begin{array}{l}\text { Endometrial } \\
\text { hyperplasia }\end{array}$ & 11 & - & 06 & 05 & 16.05 \\
\hline $\begin{array}{l}\text { Endometritis, } \\
\mathrm{Cu}-\mathrm{T}\end{array}$ & 01 & - & 1 & - & 12.0 \\
\hline Total & $124 *$ & 08 & 100 & 16 & $\begin{array}{l}9.56 \\
S D=4.27\end{array}$ \\
\hline
\end{tabular}

$\mathrm{n} \neq 110$ as

- 5 patients had polyp and endometrial hyperplasia

- 9 patients had fibroid and adenomyosis

In forty $(36 \%)$ cases the TVS could not detect any abnormality. All eight cases of intramural fibroid were diagnosed however two cases of posterior wall submucous myoma were mistaken as intramural myoma. Three cases of polyp with broad base were mistaken as case of endometrial hyperplasia while four cases of polyp were falsely reported as normal. Three cases of focal hyperplasia were reported as polyp. Endometrial stripe thickness of less than $5 \mathrm{~mm}$ was considered to represent cases of atrophy which was noted in five cases. Two cases each of disordered proliferative endometrium were misreported as polyp and hyperplasia.

\section{Hysteroscopic findings}

After thorough work-up and informed consent all women were subjected to hysteroscopy. A good visualization of entire uterine cavity without any structural abnormality and uniformly appearing endometrium was possible in sixty - two $(56 \%)$ cases. Proliferative endometrium defined as smooth and thin with pinkish velvety appearance was noted in $54(49 \%)$ cases while $8(7.2 \%)$ cases had secretory endometrium appearing as thick, orange, edematous lining without any visible arteries. Hysteroscopy appeared to be sensitive enough to diagnose almost all cases of submucosal fibroid and polyp (Table 4). 
Table 3: Distribution of cases in comparison to final diagnosis showing sensitivity (S), specificity (Sp), positive predictive value (Ppv), negative predictive value (Npv) of transvaginal songraphy (TVS).

\begin{tabular}{|c|c|c|c|c|c|c|c|c|c|c|}
\hline \multirow{3}{*}{ Etiology $(\mathrm{n}=124) *$} & \multirow{2}{*}{\multicolumn{2}{|c|}{ No. of cases }} & \multicolumn{4}{|c|}{ TVS } & \multirow{3}{*}{$\mathbf{S}$} & \multirow{3}{*}{ Sp } & \multirow{3}{*}{ PPV } & \multirow{3}{*}{ NPV } \\
\hline & & & \multicolumn{2}{|c|}{ True } & \multicolumn{2}{|c|}{ False } & & & & \\
\hline & TVS & $\begin{array}{l}\text { Final } \\
\text { diagnosis }\end{array}$ & $\begin{array}{l}+ \\
(\mathrm{A})\end{array}$ & $\begin{array}{l}- \\
\text { (D) }\end{array}$ & $\begin{array}{l}+ \\
\text { (B) }\end{array}$ & $\begin{array}{l}- \\
(\mathrm{C})\end{array}$ & & & & \\
\hline Proliferative & 36 & 34 & 26 & 66 & 10 & 8 & 76 & 87 & 72 & 89 \\
\hline Secretory & 6 & 6 & 04 & 102 & 2 & 2 & 67 & 98 & 67 & 98 \\
\hline Atrophic & 7 & 7 & 05 & 101 & 2 & 2 & 71 & 98 & 71 & 98 \\
\hline Fibroid submucous* & 22 & $24 *$ & 22 & 86 & - & 2 & 85 & 100 & 100 & 98 \\
\hline Fibroid intramural* & 10 & $8^{*}$ & 8 & 100 & 2 & - & 100 & 98 & 80 & 100 \\
\hline Polyp & 21 & 22 & 15 & 82 & 6 & 7 & 68 & 93 & 71 & 92 \\
\hline Adenomyosis & 12 & 15 & 10 & 93 & 2 & 5 & 67 & 98 & 83 & 95 \\
\hline Endometrial hyperplasia & 13 & 11 & 7 & 93 & 6 & 4 & 63 & 94 & 54 & 96 \\
\hline Inflammatory & 1 & 1 & 1 & & & - & 100 & & 100 & \\
\hline
\end{tabular}

* Total Fibroid cases were 28; four had both submucous and intramural fibroid

Table 4: Distribution of cases in comparison to final diagnosis showing sensitivity (S), specificity (Sp), positive predictive value (Ppv), negative predictive value (Npv) of diagnostic hysteroscopy (DH).

\begin{tabular}{|c|c|c|c|c|c|c|c|c|c|c|}
\hline \multirow{3}{*}{ Etiology $(\mathrm{n}=124) *$} & \multirow{2}{*}{\multicolumn{2}{|c|}{ No. of cases }} & \multicolumn{4}{|l|}{ DH } & \multirow{3}{*}{$\mathbf{S}$} & \multirow{3}{*}{ Sp } & \multirow{3}{*}{ PPV } & \multirow{3}{*}{ NPV } \\
\hline & & & \multicolumn{2}{|c|}{ True } & \multicolumn{2}{|c|}{ False } & & & & \\
\hline & DH & $\begin{array}{l}\text { Final } \\
\text { diagnosis }\end{array}$ & $\begin{array}{l}+ \\
(\mathrm{A})\end{array}$ & $\begin{array}{l}- \\
\text { (D) }\end{array}$ & $\begin{array}{l}+ \\
\text { (B) }\end{array}$ & $\begin{array}{l}- \\
(\mathrm{C})\end{array}$ & & & & \\
\hline Proliferative & 54 & 34 & 32 & 54 & 22 & 2 & 94 & 71 & 59 & 96 \\
\hline Secretory & 8 & 6 & 6 & 102 & 2 & - & 100 & 98 & 75 & 100 \\
\hline Atrophic & 5 & 7 & 5 & 103 & - & 2 & 71 & 100 & 100 & 98 \\
\hline Fibroid submucous* & 23 & 24 & 22 & 85 & 1 & 2 & 92 & 99 & 96 & 98 \\
\hline Fibroid intramural* & 2 & 8 & - & 100 & 2 & 8 & & 98 & 100 & 93 \\
\hline Polyp & 22 & 22 & 20 & 86 & 2 & 2 & 91 & 98 & 91 & 98 \\
\hline Adenomyosis & - & 15 & - & 95 & - & 15 & & 100 & & 86 \\
\hline Endometrial hyperplasia & 13 & 11 & 9 & 95 & 4 & 2 & 82 & 96 & 69 & 96 \\
\hline Inflammatory / CuT & 1 & 1 & 1 & 109 & - & - & & 100 & 100 & 100 \\
\hline
\end{tabular}

Polyps were seen as soft, oval and pedunculated growths with smooth surface while submucous myoma appeared as roundish, white bulge in the uterine cavity. Two cases with multiple myoma with inadequate view and distorted cavity, submucous myoma were mistakenly reported as intramural myoma. One case with large intramural fibroid gave appearance of submucous myoma on hysteroscopy. Two cases of focal hyperplasia were seen as polyp while in two women with disordered proliferative endometrium false reporting of hyperplasia was made. All cases of adenomyosis and seven out of eight cases of intramural fibroid were reported as normal. Atrophic endometrium appearing as thin fragile and flat surface was seen in five cases. Hysteroscopy appeared to be safe enough without any significant complications in our series. Hysteroscope could not be negotiated in three cases due to cervical stenosis and these three cases were excluded out of the study.
Table 5: Correlation of final diagnosis with transvaginal sonography and hysteroscopic findings.

\begin{tabular}{|lll|}
\hline $\begin{array}{l}\text { Investigation } \\
\text { Findings }\end{array}$ & $\begin{array}{l}\text { Agreement } \\
\text { between } \\
\text { TVS \& final } \\
\text { diagnosis }\end{array}$ & $\begin{array}{l}\text { Agreement } \\
\text { between } \\
\text { DH \& final } \\
\text { Diagnosis }\end{array}$ \\
\hline Proliferative & 26 & 32 \\
\hline Secretory & 4 & 6 \\
\hline Atrophic & 5 & 5 \\
\hline $\begin{array}{l}\text { Fibroid } \\
\text { submucous }\end{array}$ & 22 & 22 \\
\hline $\begin{array}{l}\text { Fibroid } \\
\text { intramural }\end{array}$ & 8 & - \\
\hline Polyp & 15 & 20 \\
\hline Adenomyosis & 10 & - \\
\hline $\begin{array}{l}\text { Endometrial } \\
\text { hyperplasia }\end{array}$ & 7 & 9 \\
\hline Cu-T & 1 & 1 \\
\hline
\end{tabular}




\section{DISCUSSION}

Abnormal uterine bleeding (AUB) is a common problem affecting the woman of entire age spectrum. As the etiologies behind the abnormal bleeding patterns are many, diagnostic work up of such cases is often a daunting task. Determining the exact cause is important not only to initiate appropriate corrective measures but also to rule out malignancy in high risk groups. When the cost and time are a consideration, subjecting a woman to a battery of investigations is definitely not desirable, especially in low resource settings. Hysterectomy, the only true gold standard, will be too impractical in each and every case. A rapid, safe, effective, sensitive, cost effective and less invasive tool would be ideal. Between the debate of invasive and non- invasive, picking up a diagnostic tool is often not easy. With recent revolution in technology, there is a shifting interest towards hysteroscopy as a minimally invasive, rapid, safe and accurate procedure for primary evaluation of architectural abnormalities of the uterine cavity. However, hysteroscopy requires an acquisition of surgical expertise and it is still not available as out-patient procedure in many resource limited centres. Executing hysteroscopy as an inpatient procedure mandates administration of anaesthesia besides the cost of surgery and hospital stay. Transvaginal sonography although brings about indirect assessment of intrauterine cavity is safe, sensitive, cost effective and non - invasive tool for mapping structural pathologies in abnormal uterine bleeding. Present study was undertaken to evaluate the role of two commonly employed diagnostic methods in the investigation of abnormal uterine bleeding.

Although abnormal uterine bleeding affects the woman of all ages, it largely affects the woman of reproductive age. The mean age of participants in our study was 41.9 years which is similar to the observations made by Christopher $\mathrm{D}$ et al and Theresa Wildrich et al. in their study group. ${ }^{1,2}$ Nancy A et al. found $90 \%$ cases to be multiparous which is similar to observation made in our $\operatorname{study}(95 \%){ }^{3}$ Abnormal uterine bleeding can take many forms of presentation. In reproductive age group, AUB usually manifests as menorrhagia and metrorrhagia. Jaiswal Shyam pyari et al. noted menorrhagia in $40 \%$ cases and metrorrhagia in $18 \%$ cases. $^{4}$

Franklin D et al. in their study population of 187 cases noted that $59.4 \%$ cases of abnormal uterine bleeding had no detectable pathology on examination. ${ }^{5}$ Fibroid and polyp are the two commonest structural abnormality in women with AUB in reproductive age group. Nancy A et al found fibroid in $34 \%$ cases while polyp in $23 \%$ of cases. On correlation of various pathology with the respective mean age Lawrence $\mathrm{P}$ et al found that women with endometrial cancer, hyperplasia and atrophy were significantly older $(p<0.007)$ than the women with myoma and proliferative endometrium. ${ }^{6}$ In our study also cases of hyperplasia and atrophy had higher mean age as compared from the women with fibroid, polyp and normal endometrium. Endometrial stripe measurement on sonography has been variously studied to predict intrauterine pathology. In the study conducted by Lawrence $\mathrm{P}$ et al. patients of endometrial atrophy demonstrated significantly thinner endometrium (mean $4.4 \mathrm{~mm} ; \mathrm{p}<0.0003$ ) compared from those diagnosed to have adenocarcinoma $(17.7 \mathrm{~mm} ; \mathrm{p}<0.0003) .{ }^{6}$ In the current study women with endometrial hyperplasia and polyp demonstrated thicker endometrium while those with atrophy had thinner endometrium. Different studies have tried to define endometrial thickness cut offs for different pathology however patients symptoms take precedence over endometrial stripe measurements when deciding about the management. Nancy A et al. noted lesions at hysteroscopy in 3 out of 4 cases with endometrial stripe measurements less than $5 \mathrm{~mm}$ on transvaginal sonography. ${ }^{3}$ Similarly, Lawrence $\mathrm{P}$ et al. noted one well differentiated endometrial carcinoma, six cases of polyp and two submucous myoma in eight women with endometrial thickness less than $5 \mathrm{~mm} .{ }^{6}$ Many authors propose transvaginal sonography to be used as primary screening tool in cases of AUB as it defines myometrial and adnexal abnormalities also. In our study, six cases of simple ovarian cysts were detected on sonography. All cases of intramural fibroid and adenomyosis that were missed on hysteroscopy were picked up on sonography. On correlation of TVS findings with final diagnosis, it was noted that TVS had a fair agreement with final diagnosis. TVS although safe, sensitive and well tolerated has limitation in defining small focal pathology especially which are isoechoic with adjacent endometrium. Two cases of posterior wall myoma which were difficult to visualize were mistaken as intramural myoma. Three women with disordered proliferation were misdiagnosed as cases of hyperplasia. Also, three cases of focal hyperplasia were mistaken as polyp in our series. Cynthia Farqhar in their systematic review reported the sensitivity of TVS in detection of submucous fibroid to range from $21 \%$ to $100 \%$ and specificity from $53 \%$ to $100 \%$ in different studies. ${ }^{7}$ Similarly, for hyperplasia TVS had sensitivity ranging between 33 and $100 \%$ and specificity between 79 and $99 \%$ in the same review. ${ }^{7}$

In our series, three women with AUB could not undergo hysteroscopy due to cervical stenosis and were excluded out of the study. In fifty - four (49\%) cases the hysteroscopic view was normal which is comparable to observation made by Sima M et al. ${ }^{8}$ Jaiswar S P et al. found myoma (34\%) as commonest pathology on hysteroscopy. ${ }^{4}$ In the systematic review of Cynthia hysteroscopy had a sensitivity ranging from 53 to $100 \%$ and specificity between $97 \%$ and $100 \%$ in detection of submucus fibroid. ${ }^{7}$ In our study, submucus fibroid (21\%) and polyp (20\%) were the most frequent structural abnormality on hysteroscopy. Hysteroscopy was sensitive enough to pick up fibroid and polyp (sensitivity $92 \%$ and $91 \%$ respectively), the two commonest lesions seen in women with abnormal uterine bleeding in reproductive age group. Hysteroscopy lacked sensitivity in detection of adenomyosis and intramural myoma which were well 
reported on transvaginal sonography. On final correlation, although hysteroscopy and sonography had fair agreement, both had complementary role and helped in taking management decisions. Transvaginal sonography being sensitive, non-invasive, safe and cost effective should be used for initial assessment of abnormal bleeding and selection of cases for formal evaluation by hysteroscopy. The limitation of our study was that we could not time the sonographic examination in particular phase of menstrual cycle. Also the examination at times was carried out in bleeding phase which could have affected the endometrial stripe measurements. Further studies may be undertaken to develop a nomogram to triage women for thorough evaluation by hysteroscopy.

\section{CONCLUSIONS}

In many cases of AUB, there is no underlying organic pathology. Fibroids and polyps are the two commonest structural lesions causing AUB in the women of reproductive age group. TVS has a role as primary screening method for the initial work-up AUB before resorting to invasive procedure such as hysteroscopy. Both TVS and hysteroscopy are complementary to each other and help to take management decisions in women with AUB.

\section{Funding: No funding sources}

Conflict of interest: None declared

Ethical approval: The study was approved by the institutional research advisory committee and ethics committee

\section{REFERENCES}

1. Christopher D. Williams, Paul B. Marshburn. A propective study of transvaginal hydrosonography in the evaluation of abnormal uterine bleeding. Am J Obstet Gynecol. 1998;179:292-8.

2. Theresa Widrich, Linda Bradley, Allison R, Mitchinson. Comparison of saline infusion sonography with office hysteroscopy for the evaluation of the endometrium. Am $\mathbf{J}$ Obstet Gynecol. 1996;174:1327-34.

3. Nancy C Lee, Richard C Dicker, George L Rubin, Howard W Ory. Confirmation of the preoperative diagnoses for hysterectomy. Am J Obstet Gynecol. 1984;150:283-7.

4. Jaiswar SP, Sochan R, Shrivastava PK, Goel M, Pandey M. A comparative diagnostic evaluation of hysteroscopy, transvaginal ultrasonography and histopathological examination in cases of abnormal uterine bleeding. J Obstet Gynecol India. 2006;56:240-3.

5. Franklin D Lofter. Hysteroscopy with selective endometrial sampling compared with D\&C for abnormal uterine bleeding: the value of negative hysteroscopic view. Obstet Gynecol. 1989;73:16-20.

6. Lawrence P. O'Connell, Melissa H. Fries, Ernest Zeringue, Walter Brehm. Triage of abnormal postmenopausal bleeding: A comparison of endometrial biopsy and transvaginal sonohysterography versus fractional curettage with hysteroscopy. Am J Obstet Gynecol. 1998;178(5):956-61.

7. Cynthia Farquhar, Alec Ekeroma, Susan Furness, Bruce Arroll. A systematic review of transvaginal ultrasonography, sonohysterography and hysteroscopy for the investigation of abnormal uterine bleeding in premenopausal women. Acta Obstet Gynecol Scand. 2003;82:493-504.

8. Sima Mukopadhyay, Bhattacharya SK, Ganguly RP, Patra KK, Bhattacharya N, Barman SC. Comparative evaluation of perimenopausal abnormal uterine bleeding by transvaginal sonography, hysteroscopy and endometrial biopsy. $\mathbf{J}$ Indian Med Assoc. 2007;105:624-30.

9. Sheetal G Patil, S B Bhute, S A Inamdar, Neema S Acharya and Deepti S Shrivastava. Role of Diagnostic Hysteroscopy in Abnormal Uterine Bleeding and its Histopathologic Corelation. J Gynecol Endosc Surg. 2009 Jul - Dec;1(2):98-104.

10. E. Dreisler, S. Stampe Sorensen, P. H. Ibsen and G. Lose. Value of endometrial thickness measurement for diagnosing focal intrauterine pathology in women without abnormal uterine bleeding. Ultrasound Obstet Gynecol. 2009;33:344-8.

DOI: $10.5455 / 2320-1770 . i j r \operatorname{cog} 20140309$

Cite this article as: Jain M, Kanhere A, Jain AK. Abnormal uterine bleeding: a critical analysis of two diagnostic methods. Int J Reprod Contracept Obstet Gynecol 2014;3:48-53. 